\title{
Teachers' Oral Error Correction in Algerian EFL Classrooms
}

\author{
Siham BOUZAR \\ English Department, University of Algiers 2, Algeria \\ E-mail: Siham_bouzar@hotmail.com
}

Received: June 2, $2020 \quad$ Accepted: July 2, 2020 Published: July 5, 2020

doi:10.5296/elr.v6i2.17311 URL: https://doi.org/10.5296/elr.v6i2.17311

\begin{abstract}
The largest part of the time spent in our daily life communication is attributed to speaking. This skill allows the transmission of ideas, feelings, attitudes and information to the hearer through speech. It is in fact very crucial for any language learning efficiency development. However, expressing oneself orally sometimes constitutes a source of frustration for EFL learners as it is very demanding and requires the teachers' intervention whenever errors are made. Therefore, with the perspective to promote the target language learning and assist students in their learning process, the strategies used by teachers to give their feedback about oral errors at the level of the language classroom constitutes the object of this study.
\end{abstract}

Keywords: Speaking skill, Oral Error, Oral error correction

\section{Introduction}

A great deal of studies on oral correction (Lyster \& Ranta, 1997; Morshada, 2007; Coskun, 2010; Tomkova, 2013; Jing et al., 2013; Fakazli, 2018; Alkhammash, 2019) which has been carried out during the last two decades indicates that the spoken skill as well as the correction attributed to it are significant elements requiring to be addressed. They constitute an extensive area of research to be dealt with by non-native speakers. Accordingly, this survey aims at investigating teachers' intervention in the language classroom with specific focus on oral error corrections in Algerian EFL classrooms. It also attempts to answer some issues relating to students' oral error types, teachers' correction time and the strategies for intervention. In this framework the following major question stands out:

- How do teachers intervene to correct their learners' oral errors?

Likewise, some sub questions are raised. These have to do with:

- What types of oral errors do EFL learners fall in?

- When do teachers implement their intervention strategies? 


\section{Significance of the Study}

As it has been mentioned previously, there have been many studies taking place in EFL context; however, researches dealing with oral errors correction in North Africa are rare especially in Algeria. To fill this gap, it is important to increase teachers' awareness of the different ways of correction. This study, therefore, will contribute to enhance the teaching and learning in Algeria, as all teachers have problems in dealing with the correction of their learners' errors especially in oral production. The present work gives opportunity to discover and understand EFL teachers' behaviours and instruction in classrooms. Additionally, it will enhance EFL teachers' ability to reflect critically on their instruction and professional development in general; and their correction in particular.

\section{Background of the Study}

Many studies dealing with teachers' intervention to improve the teaching of speaking to EFL learners have been carried out during the last two decades; therefore, highlighting the difference existing between a mistake and an error as well as the issues relevant to the timing of correction and the appropriate strategies for intervention learners require to be addressed.

\subsection{Errors: Generalities}

This section deals with the different aspects related to errors namely the definitions attributed to them, how to differentiate between them and a mistake, the nature of errors and the types of the latter.

\subsection{Definition of Error}

Error has received various definitions by diverse researchers. For instance, Hendrickson (1978) defines error as "an utterance, form or structure that a particular language teacher deems unacceptable because of its inappropriate use or its absence in real- life discourse" (p 387). James (1998) gives another definition to error. He states that "Errors can be seen as foreign language learners' ignorance of the target language'" (p. 63). Furthermore, a simple definition was given by Chun et al. (1982) who define error as "a linguistic item in a way, which according to fluent users of the language indicated faulty or incomplete learning" (p 538).

\subsection{Difference between Mistake and Error}

In the area of second and foreign language teaching, it is important to distinguish between mistakes and errors. According to the Dictionary of Language Teaching and Applied Linguistics (1992), a learner makes a mistake when writing or speaking because of the lack of attention, fatigue, carelessness or some other aspects of performance. Mistakes can be self-corrected when attention is called. However, an error is the use of linguistic item in a way that a fluent or native speaker of the language regards it as showing faulty or incomplete learning. In other words, it occurs because it cannot be self-corrected as the learner does not know what is correct.

Ellis (2005) suggests two ways that help to distinguish between mistakes and errors. The first one is to check the consistency of learner's performance. If he sometimes uses the correct form and sometimes the wrong one, it is a mistake. However, if he always uses it incorrectly, it is then an error. The second way is to ask the learner to try to correct his own deviant utterance. That is, if the learner is able to correct what is wrong, the deviations are errors. Yet, in case he is successful, the wrong utterances are considered as mistakes. 
3.4 Nature of Errors

While learning English as a foreign language, it is impossible to avoid making errors. There are two major views on the nature of errors. The first view is the contrastive analysts view which claims that the occurrence of errors is due to first language (L1) interference. However, this view was criticized by many studies suggesting that the theoretical views raised by the contrastive analysis failed to give a clear explanation to all the types of error. Teachers also criticized the contrastive analysis results claiming that many errors noticed in classroom were not predicted by the contrastive analysis (Nemser, 1984).

The weaknesses of CA shifted emphasis from contrastive analysis view to error analysis view. The latter is the second view which claims that the occurrence of errors is due to many reasons such as fossilization, overgeneralization, and misteaching. It demonstrates that CA was unable to predict all errors. What makes error analysis different from contrastive analysis is that it observes analyses and classifies errors.

\subsection{Oral Error Types}

It is not always the case teachers want or need to correct all errors in oral production. So before reporting the different perspectives regarding correction, it is important to identify the types of oral error. These types have been categorized differently. Firstly, Corder (1973) classified them into four categories namely: errors of omission (where some element is omitted that should be present); errors of addition (where some element is present though it should not be there); errors of selection (where a wrong form was selected in place of the right one); and errors of ordering (where the items presented are selected correctly, but placed in a wrong order). Then, linguists started to classify oral errors by relying on the linguistic aspects. One of these linguists is Chaudron (1988) who classified oral errors into six categories namely phonological, lexical, morphological, syntactic, discourse and content ones. A more clear classification was given by Lyster and Ranta (1997) who categorized oral errors into four types namely: grammatical, lexical, phonological, and use of L1.

\section{The Significance of oral Errors and Correction}

In the present study, the concepts error correction and corrective feedback are used alternatively. Many linguists support Krashen's hypothesis and clarify the importance of errors. One of these linguists is Corder (1967) who argues that teachers should accept their students' errors only because they can help them to check their learners' development and the effectiveness of their teaching methods and techniques. He also points out that errors can help teacher discover the different strategies their students use to learn the language. He illustrates the significance of learner errors in several ways. He states that learners' errors are important for teachers as they indicate the amount of information that the learner has acquired, and teachers can then modify their instruction according to their learners' needs. Therefore, errors were considered as important elements of the learning process. Besides, if teachers correct all the errors they will fail in their role as supportive mentors.

Another argument supporting errors making was given by Hendrickson (1978) who claims that since parents anticipate and accept their children's errors as a natural process of acquiring and developing their native language, foreign language teachers should expect errors made by their students as a natural experience to the process of learning a second or a foreign language. In 
addition, Doff(1993) states that errors are beneficial for both teachers and learners. They help them to know what their learners have learned and what they have not. Besides, errors help teachers to discover what they still require to teach. He also claims that while prohibiting learners from making errors, teachers will not know what their learners still need. In this framework, Broughton et al. (2003) point out that "a learner must make errors as an unavoidable and necessary part of the learning process, so errors are not the bad thing once thought but visible proof that learning is taking place" (p. 135).

While many linguists and researchers on the field of error correction endorse the occurance of errors, other linguists disfavor errors and illustrate the significance of correction. They also support swain, Schmidt, and long hypotheses. For instance, Edge (1989), suggests that learners will learn better and try to understand the language when they are engaged in correction. In addition, Harmer (1998) suggests that correction helps learners construct their language. $\mathrm{He}$ claims that students' errors should be corrected because students make errors and mistakes but they do not know what their errors are exactly, and what their importance is.

\section{Oral Corrective Feedback}

Learners make errors in oral practice because they are required to produce something in the target language. These studies show that Teachers' correction and attitudes towards correction differ and depend on their views of language teaching. They are also based on their own previous L2 learning experiences. Some teachers refute error correction while others adhere to correct errors. They also demonstrate when correction should be done and how to give feedback.

\subsection{Timing of Correction}

Although many studies demonstrated the effectiveness of error correction, researchers consent that its effectiveness depends on different factors namely the timing of correction. According to Chaudron (1988), it is the teacher who is responsible of determining the appropriate type of correction and the suitable time for that. The latter depends on the teachers' views on language and on the approaches of teaching they rely on. In fact, timing of correction differs from one method of teaching to another.

In the grammar translation method and the audio lingual one, learners receive an immediate correction. Broughton et al. (2003) that immediate feedback is vital for learners as it allows them to know how well they have understood the newly learnt forms. This timing of correction is also supported by the behaviourists who suggest that errors should be corrected as soon as they occur because they may cause fossilization. They consider learning as a habit formation where errors constitute a signal of failure. Belbin et al. (1970) defend the behaviourists' view suggesting that errors inhibit the learning process. In the same frame work, Bartram \& Walton (1991) state that "often the spontaneous reaction on hearing an error is to correct immediately" (p. 4). However, some teaching approaches were against immediate correction and indicate that delayed correction or ignorance of errors is the best way to help learners develop their interlanguage.

The communicative language teaching approach refuted the behaviourists' view. The errors in this method are regarded as a natural process through which learners go while acquiring a new language and represent a proof to teachers that learning is taking place. This approach believes 
that learning a second language is similar to first language acquisition in terms of the mistakes resulting from the process of getting in the language. Yet, this approach suggests that errors that prevent the flow of communication should be corrected (Prabhu, 1987; Burt \& Kiparsky, 1972; Corder, 1974; Hendrickson, 1978; Truscott, 1996). Thus, communicative language teaching views errors as an essential part of the learning process and not as a negative aspect of learning contrary to the previous approaches. The naturalists also were against correcting oral errors. According to them, they should be ignored because correction affects motivation negatively and disturbs the flow of communication. Therefore, instructing the target language in this approach is very challenging as the teacher is not allowed to interrupt learners while expressing themselves.

Many linguists were in support of delayed correction. Brown (2007) for instance proposes that delayed correction is more suitable for communication activities. Besides, conducting a delayed correction all learners can benefit from the correction. Another linguist who was in favour of delayed correction is Mendelson (1990) who states that in oral production learners should be corrected till they finish interacting in order to avoid interrupting their communication. Other linguists suggested that the timing of correction depended on different factors. According to Scrivener (2005), the time of correction is based on the goal of the activity. For example, if the objective is accuracy, immediate correction is appropriate; however, if the focus is on fluency, later correction is called for as it "...could kill the activity" (ibid, 111).

\subsection{Strategies for Oral Error Correction}

Different terminologies and classifications were adopted to denote the strategies used when providing feedback on an oral performance. Lyster and Ranta (1997: 46), for example, suggested six types of corrective feedback namely "explicit correction, Recast, clarification request, Metalinguistic feedback, elicitation and repetition".

Explicit correction, according to them, refers to the explicit provision of the correct form. As the teacher provides the correct form, he or she clearly indicates that what the student had said was incorrect. As concerns recast strategy, it is generally implicit and involves the teacher's reformulation of all or part of a student's utterance, minus the error. Concerning clarification request strategy, it refers to problems in connection with either comprehensibility or accuracy, or both. It indicates to students either that their utterance has been misunderstood by the teacher or that the utterance is ill-formed in some way and that a repetition or a reformulation is required. As regards metalinguistic feedback, "it contains either comments, information, or questions related to the well-formedness of the student's utterance, without explicitly providing the correct form" (Lyster \& Ranta,1997: 47). Elicitation as another type of corrective feedback includes pauses allowing students to fill in the blanks, questions eliciting correct forms, reformulating utterances by students. Repetition, as the last strategy for oral error correction, refers to highlighting the student's erroneous utterance by adjusting its tone or its inflection. It is worth noting in this context that the feedback types aforementioned can be implemented in the language classroom individually or by a combination of more than one strategy. 


\section{Empirical Studies dealing with Oral Correction}

This section summarizes the previous studies done on error correction. Subsequently, it recaps the studies conducted on oral errors, errors correction; the ways and timing of correction. Chronologically, the early studies are presented first, then the recent ones. Dekeyser (1993) conducted a quasi-experimental study to examine the effect of error correction in two high school classes of French as a second language in Belgium for a full school year. One teacher was asked to correct the students as frequently and as explicitly as possible during communicative activities, whereas the other was asked to avoid correction in such activities. The teaching was observed periodically, and the analysis of the teachers' behaviour confirmed that the treatments were being implemented as expected. To evaluate the effect of the error treatment, a variety of measures of L2 proficiency were administered at the beginning and at the end of the school year. In addition, measures of learner variables such as foreign language learning aptitude, extrinsic motivation, and anxiety were also collected. Results show that error correction did not have an overall effect on student proficiency in the L2 but that it did interact with learner variables. Lyster and Ranta (1997), in their study on corrective feedback and learners' uptake in four immersion classrooms at the primary level results, 18.3 hours of classroom interaction taken from 14 subject-matter lessons and 13 French language arts lessons were analyzed using a model developed for the study and comprising the various moves in an error treatment sequence. Results include the frequency and distribution of the six different feedback types used by the four teachers; in addition to the frequency and distribution of different types of learner uptake following each feedback type.

Another observational study was conducted by Sheen (2004) who compared teacher feedback and student uptake across instructional settings. Four communicative classroom settings, namely French immersion (Lyster \& Ranta 1997), Canada ESL (Panova \& Lyster, 2002), New Zealand ESL (Ellis et al., 2001) and Korean ESL (Sheen, 2007), were inspected using the taxonomy of Lyster and Ranta (1997). All of these studies used the taxonomy of Lyster and Ranta(1997) and had the same setting discourse, meaning -based, which allowed the comparison to be made. Results showed that recast was the most frequent technique of correction including 50\% of all feedback moves. Concerning the uptake, a similarity was shown between New Zealand ESL and Korean EFL had much higher rate than the Canadian contexts (immersion and ESL). Morshada (2007) in his study on error correction investigated the way error correction is done in different schools in Dhaka city and learners' response to the treatment of error. Subsequently, he aimed at knowing the types of oral errors corrected by the teachers and the strategies used to correct them. He also wanted to know whether teachers are aware of the changing trend in teaching methodology. Teachers and learners of elementary level participate in this study from different classes in different schools. He used many tools to collect data such as observation, and a questionnaire survey. Results revealed that grammatical and content errors are the most corrected ones. Concerning the way of correction, teachers used a variety of strategies to correct.

Akhter (2007) in her internship made the difference between mistake and error relying on Brown (2000) definitions. She also discussed the way errors are regarded in three methods of second language learning/teaching: the grammar-translation method, the direct method, and the communicative language teaching method. She adopted Harmer (1998) justification for 
error correction who claims that teachers' positive attitude towards correction can help learners develop their performance. She corrects students' oral errors inductively an avoided correcting grammar errors in order not to stop their communication or scared them from answering suggesting that she is following the CLT.

Another exploratory study was conducted by Hernández and Murrieta (2009) to analyze the actual role of corrective feedback in the EFL classes in the English Language Program at Quintana Roo University. Additionally, a second goal is to identify the corrective feedback techniques used by the EFL teachers in this program. Coskun (2010) in his study to present the results of a small scale classroom research carried out to collect data about his spoken error correction behaviors by means of self-correction, aimed to correct which and how errors are corrected in a beginner's class. He based his observation on the types of errors and correction introduced by Lyster and Ranta (1997). He noticed that all errors were corrected immediately by him and explicit correction was used most. Firwana (2010) conducted a study to investigate the impact of Palestinian teachers' attitudes toward oral errors on their students' attitudes and choice of oral error correction strategies. The participants of the study were hundred fifty-one (151) high elementary and secondary school Palestinian EFL teachers and seven hundred seventy-four (774) of their students. A student and a teacher questionnaire were given for the two groups. The study also included twelve (12) teacher participants who were observed and semi-structured interviewed twice in the course of the study, and twelve (12) student participants who took part in two focus group interviews. Data were collected using different tools: questionnaires, interviews, focus groups, and observations. Findings revealed that both teachers and students have positive attitudes towards oral error and correction. In addition, they showed that there is a disagreement between teachers and students regarding when, how, and which errors to correct. Results also indicated that students prefer not to be corrected in each error they make and that variety in correction strategies had different impacts on students.

Méndez et al. (2010) conducted an exploratory study to analyze the actual role of corrective feedback in the EFL classes in the English Language Program at the University of Quintana Roo. Five language instructors from the English language bachelors program at this university were interviewed by a semi-structered interview with about twenty questions. Findings show that teacher correction is the most type used in classrooms. In addition, the most frequent types of used are repetition of errors, body language, metalinguistic feedback, and recast. Results also show that instructors target their oral correction to phonological and morphosyntax errors, but semantic and pragmatic errors are the most neglected types.

Shahin (2011) in his study on errors treatment analyzed the types of errors learners make during classroom learning. He also presented an account of the strategies that teachers use to deal with these errors. For this purpose, Arab teachers were observed in their classroom teaching. Findings were compared to western teachers. He collected data through designing an observation scheme based on Frohlich and Spada's part A of the Communicative Orientation of Language Teaching (COLT) scheme. Five Arab EFL teachers at Saudi Aramco English Training centers in the Eastern province of Saudi Arabia participated in this study. Results show that lexical errors were the most treated ones and that correction was done either immediately or ignored.

Taipale (2012) conducted a descriptive study for her master thesis to investigate the ways of 
treating oral errors in EFL classrooms. Additionally, it aimed at exploring the ways students respond to their teachers' feedback. She used a structured observation. The observations were based on six hours of videotaped and audio-recorded material from two EFL classrooms in a Finnish High School in Finland. The participants were two teachers, who have both significant experience in teaching, and adolescents. Results showed that grammatical, phonological, and lexical errors are the most errors committed by the students. They also revealed that $75 \%$ of the whole errors received feedback from the teacher and that 472 of the feedback moves were followed by uptake.

Akil et al. (2013) conducted a study to investigate the oral errors teachers focus on, the procedures adopted, and timing use to correct them. Three teachers participated in the study: native, second and foreign language teachers. The results, retrieved from the analysis of the data collected through recordings, revealed that the ranking of teachers that have native like interaction is similar to second and foreign language speakers. Results also showed that the teachers focused on all types of errors and use different techniques of correction. Mahi and El Saadany (2013) on their collaborative work, wrote a chapter to investigate the kinds of feedback found in an EFL classroom, a small municipality in South Sweden with a high socioeconomic status .and the attitudes teachers and learners attitudes towards these types. The results showed that explicit feedback is the least used one due to teacher's belief that other types are more beneficial.

Russell and Spada's (2002) made a meta-analysis in which they analyzed the immediate and delayed correction based on fifteen different studies published between (1988) and (2003). Their analyses showed that error correction had a great immediate effect.

Another meta-analysis on correction was conducted by Li (2010). His analysis contained 33 different studies from the past 20 years which showed that correction has a great effect and the effect was maintained over time.

Tomkova (2013) in her exploratory study on errors in oral practice and the ways of correcting these errors, analyzed and evaluated the different aspects of errors and correction. Data were gathered from 48 teachers of English in the Czech Republic and 150 learners aged between 13 and 20 by means of questionnaire (11 questions) for both teachers and learners in order to compare their opinions about error correction. Results showed that more than $50 \%$ of students feel to be corrected by their teachers, and the rest feel to be corrected sometimes. Concerning students' satisfaction on correction, the majority of students were satisfied. Results also revealed that most students related the correction in speaking to the type of the activity. One third of students felt that correction was done the same way with all types of activities; however, one in five students claimed that students did not get the same way of correction. Students also prefer explicit correction and consider the ignorance of errors as something bad. Based on both formal and informal observations in the context of immersion programs in Canada Swain, (1985) suggested the importance of the Output Hypothesis, arguing that pushing learners to produce output assists language development as it provides the learner with the opportunity to practice, to notice the gap between their IL and their TL, and to offer them the chance to test their IL hypotheses.

\section{Methodology}


With the perspective to find answers to the aforementioned issue, this research was processed through a classroom research method which has as a primary purpose to provide new insights, explore phenomena, and give further understanding into the EFL teaching/learning processes. The main focus in this method is the classroom itself where both teachers and learners are observed, and all sorts of interaction between teachers and learners are available.

\subsection{The Setting}

As it has been stated previously, the present research focuses on investigating how teachers intervene in the language classroom to provide corrective feedback Therefore, the present study was established in Algeria at the level of the English department of the University of Algiers 2.

\subsection{The Subjects}

The research involved two groups of graduate informants belonging to first year English LMD who were taught by two teachers of English. The two groups containing 43 and 38 students respectively were observed thoroughly during three sessions lasting 90 minutes each one.

\subsection{Research Tools}

We made use in the present research of an observation scheme as a tool to gather the quantitative data necessary to answer the enquiry previously raised. This tool was mainly geared at gathering data relevant to the students' oral error types (grammatical, lexical, phonological and discourse), the timing of the teachers' intervention (immediate, delayed and ignored) and the strategies implemented to give feedback (recast, explicit, clarification and request, metalinguistic clues, elicitation, repetition, multiple correction and body language).

\subsection{Research Procedure}

Data was collected during three weeks time where both teachers and the two groups were observed. To collect enough data, we attended a total of eighteen (18) classroom episodes. Each class of the two teachers was observed three times.

The data collection approach is a quantitative that is guided by a structured observation scheme which record entries of events and instances related to the focus of the study. In addition, some additional examples were recorded to better understand the data analysis of each category. For this purpose, we relied upon the frequency counting method whereby numbers of errors, the strategies, as well as the timing of correction teachers provided were counted each time. This was done through filling the observation scheme with the occurrence of each target instance. Accordingly, any observed item in connection with our study focus was recorded in the scheme in its appropriate category.

\subsection{Data Analysis}

Since we have adopted an observation scheme to collect the data serving this investigation, it will be logical to tabulate information into relative frequencies through event sampling in which we will count the number of entries recorded. Our data will be displayed into drawn matrixes. Each matrix represents a scheme category where the rows show the observed elements and the columns represent the frequency. Additionally, since we have adopted a frequency counting method, data will be tabulated.

Data were analyzed using descriptive statistics. Entries of recorded behaviors were counted 
and used into percentages frequencies which were discussed as findings. Thus, the method of data analysis used in this study is frequency counting and percentages. So, it should be considered that the frequency counting has been calculated and summed up into percentages.

The following section is concerned mainly with the analysis of the collected data and interpretation of the results. It seeks at finding answers to the previous research questions raised at the beginning.

\section{Research Results}

This part of the research exhibits the results retrieved from the data collected and attempts to find explanation to the results through the implementation of tables and figures.

\subsection{Error Types}

The analysis of data revealed that the errors made students differed considerably between the two teachers' classes. In teacher 1 classes, lexical (39\%) and phonological errors (62\%) were the most frequent. However, in teacher 2 classes, the two previous errors were also noticed with different percentage $25 \%$. Additionally, grammar errors (37.5\%) which were nonexistent with teacher 1 appeared with teacher 2.

As the frequency grids shows, it is evident that the errors made differ considerably between the two teachers' classes. That is, in teacher 1 classes, phonological error s were the most frequent. However, in teacher 2 classes, both grammatical and phonological errors are similarly the most frequent.

\subsection{Error Correction Timing and Strategy Use}

When faced to learners' errors, teachers may choose the timing in which they correct errors. As the analysis of data showed, with teacher 1, immediate correction (100\%) seems to be the most frequent type of correction timing with an absence of delayed correction and ignored one. However, the results revealed that teacher 2 varies his types of timing with a high frequency in immediate correction (56\%) whereas delayed and ignored corrections scored $33 \%$ and $11 \%$ respectively.

It is evident that when teachers are faced to learners' errors, they choose the appropriate timing to intervene and introduce correction.For instance, with teacher 1, immediate correction is the most frequent type of correction timing with a rare frequencyt of delayed and ignored types. However, teacher 2 varies his types of timing with a high frequency in immediate correction.

\subsection{Strategies of Oral Correction}

As regards the strategies implemented to correct oral errors made by students, the strategies used by the two teachers were approximately the same. Both of them employed recast strategies, explicit correction, repitition and body language while they ignored the use of clarification request strategies, metalinguistic clues, elicitation and multiple correction strategies.

The strategies used by the two teachers were approximately the same. This can indicate that awareness about strategies of error correction can make a difference in the teacher's performance in this process. It can also reflect the teacher's beliefs about errors and errors correction. It appears that teacher2 is more open to correction than theacher1.

In the next section, a discussion of the results will be developed with reference to the literature 
tackling our topic.

\section{Discussion}

This section is concerned with scrutinizing, discussing and interpreting the analyzed data. The latter was collected from live instances of learners' erroneous utterances and teacher's oral correction from authentic EFL classrooms with the perspective to forward new insights about the topic.

\subsection{On Oral Error Types}

The results of the data analysis revealed that the errors made differed considerably between the two teachers' classes. In teacher 1 classes phonological error s were the most frequent. However, in teacher 2 classes both grammatical and phonological errors are similarly the most frequent. It could be assumed that teacher 1 learners have problems with phonological patterns due to the lack of exposure to the target language and the teacher's focus on phonological practices. Accordingly, errors can be seen as foreign language learners' ignorance of the target language (James, 1998 as cited in Tomkova, 2013). Another item to be pointed to is the discourse errors which recorded a minimal occurrence of one instance. The latter indicates that these classes lack communicative activities and unfamiliarity with the target language patterns. In addition, the teacher did not push learners to participate. This clearly indicates that the teacher follows the grammar translation method.

Concerning teacher 2 classes, it is clear that learners have problems with phonological and grammatical aspects of the target language. This is due to the grammatical and phonological activities taught during the three sessions. As mentioned above discourse errors are rare due to the low level of learners because the teacher was trying to motivate them and push them to communicate. This clearly indicates that the teacher is just a guide and a facilitator; he follows the communicative language teaching approach. Studies conducted by Taiple (2012), Shahin (2011) also revealed that phonological and grammatical are the most frequent contrary to lexical errors.

\subsection{On Teacher's Oral Correction Timing}

When faced to learners' errors, teachers may choose the timing in which they correct errors. As the results showed, teacher 1 immediate correction is the most frequent type of correction timing with a rare frequency in delayed and ignored types. However, teacher 2 varies his types of timing with a high frequency in immediate correction.

More clearly, teacher 1 chooses to correct her learners' errors immediately. Out of 7 instances of oral correction 6 were immediate. It could be assumed that teacher 1 is a behaviourist; she believes in Swain's out-put hypothesis (1985) that comprehensible input is not enough to ensure that learning is taking place. She adopts also Schmidt's noticing hypothesis (1990) that correction is needed to make the difference between learners' interlanguage and the target language. This also indicates that the teacher believes that learners learn better through interactional feedback (Long, 1996).

Concerning teacher 2 , he varied the timing types of correction in which immediate type is higher than other types. This indicates that the teacher sometimes is a naturalist and sometimes a structuralist. The teacher uses an approach in which correction timing differs from one group to another. This latter indicates that the teacher does not rely on his views 
towards learning but on his learners' needs and aims of activities. These finding are similar to Shahin's (2011) study findings were immediate correction and ignorance were the most correction timing used.

\subsection{On Oral Error Correction Strategies}

When observing the two teachers' classroom sessions, eight correction strategies were taken into account namely recast, explicit, clarification and request, metalinguistic clues, elicitation, repetition, multiple correction and body language. These strategies were used approximately the same way by the two teachers.

Over three sessions, teacher 1 classes yielded a total of 4 recasts and 4 explicit corrections out of 9 instances of oral corrected errors. This data refers to the tendency of this teacher to prevent errors to happen as well as to directly provide the correct form. It means that this teacher follows the behaviourists' approach to language learning. She tried to prevent her learners' oral errors as considered negative. The teacher did not take time to think about how to intervene but corrected wrong utterances following her innate feeling in preventing errors. This indicates that awareness about strategies of error correction can make a difference in the teacher's performance in this process. Studies conducted by Lyster and Ranta (1977), Panova and Lyster (2002) and Taiple (2012) also showed that recast is the most used strategy.

Teacher 2 made use of nearly all the strategies. There is however a tendency to use recast and explicit correction which is revealed through an equally devised percentage. The dispersion of percentages over almost all the strategies of oral correction may signify that the teacher adopts the communicative approach through the use of elicitation, repetition and multiple corrections which may lead learners to provide the correct form by themselves. These data also revealed that the teacher believes that no strategy is better and correction depends on his learners' characteristics and needs. In this context, Doff (1993) claims that there is not a best technique to correct errors.

To sum up, it is evident that there is no big difference between the two teachers as far as timing and strategy use are. Both of them use recast, explicit strategies and immediate correction, yet teacher 2 uses other types of timing and strategies. This small difference indicates that teacher 1 relies on his beliefs towards teaching and learning only whereas teacher 2 takes into account other factors such as the learners' level and needs, the aim of the lesson, the context in addition to his beliefs.

\section{Conclusion}

The overall aim of this study was to investigate oral correction given by EFL teachers to different types of learners' errors in oral production. Therefore, it described the investigation of two teachers' classes in an endeavor to understand different ways of teachers' oral correction. It drew attention to the significance of error types and teachers' reaction towards them. The present study presents an opportunity to discover and understand EFL teachers' behaviours and instruction in classrooms with the perspective to enable them to reflect critically on their instructional methods in general and their correction in particular. Furtheremore, the present investigation yielded some implications to be considered for the sake of promoting the target language learning and assisting students in their learning process.

Accordingly, teachers should be aware of the process of correction through developing their 
knowledge about errors and getting insights into the several existing strategies and timing of correction. Additionally, teachers should focus on the aim of the activity or the lesson to obtain a positive outcome from the students. Teachers also should vary their correction strategies to make learners pay attention to the correction and push them to self-correction which is an effective practice in oral production. Besides, teachers should listen to their learners carefully, observe them, and evaluate them individually as the requirements of each individual differ importantly from one person to another. Furthermore, teachers should take into account learners' individual differences and preferences of correction in order to serve all learners' needs and cope with all the learning styles. Finally, teachers should be self-inquirer, reflective and ask their colleagues to observe them in order to find the best ways to intervene to enhance their learners' performance.

\section{References}

Akhter, T. (2007). Giving Feedback and Correcting Errors in EFL Classroom. BRAC University, Dhaka, Bengladesh. Retrieved from https://pdfs.semanticscholar.org/dc20/382f73 a8b84abf144f92f31ed792319a35d1.pdf

Alkhammash, R. (2019). Oral Corrective Feedback Techniques: An Investigation of the EFL Teachers' Beliefs and Practices at Taif University. Arab World English Journal (AWEJ), 10(2), 40-54. https://doi.org/10.24093/awej/vol10no2.4

Bartram, M., \& Walton, R. (1991). Correction. A Positive Approach to Language Mistakes Hove: Language Teaching Publication.

Belbin, E., Downs, S., \& Moore, B. (1970).Unlearning and its relationship to age. Ergonomics, 13, 419-427. https://doi.org/10.1080/00140136408930759

Broughton, G., Brumfit, Ch., Pincas, A. \& Wilde, R. D. (2003). Teaching English as a foreign language. NewYork: Routledge.

Brown, H. D. (2007). Teaching by Principles. White Plains: Pearson Education.

Burt, M., \& Kiparsky, C (1972). The Gooficonn: A Repair Manual for English. Rowley Massachusetts. Newburg House.

Chaudron, C. (1988). Second language classrooms: Research on teaching and learning. Cambridge: Cambridge University Press.

Chun, A. E., Day, R. R., Chenoweth, N. A., \& Luppescu, S. (1982). Errors, interaction, and correction: A Study of native-non-nativeconversations. TESOL Quarterly, 16(4), 537-547. https://doi.org/10.1017/CBO9781139524469

Corder, S. (1974). Idiosyncratic Dialects and Error Analysis. In Richards, J. (Ed.). Error Analysis: Perspectives on Second Language Acquisition. 158-171. Essex: Longman.

Corder, S. P. (1967). The Significance of Learners' Errors. International Review of Applied Linguistic in Language Teaching, 5, 161-170. https://doi.org/10.1515/iral.1967.5.1-4.161

Coskun, A. (2010). A Classroom Research Study on Oral Error Correction. Humanizing Magazine Language Teaching Magazine, 12(3), 1-12.

Dictionary of Language Teaching and Applied Linguistics. (1992). Retrieved from http://www.goodreads.com/book/show/1802548.Dictionary_of_Language_Teaching_and_Ap plied_Linguistics 


\section{Macrothink}

Education and Linguistics Research ISSN 2377-1356 2020, Vol. 6, No. 2

Doff, A. (1993). Correcting Errors. Teach English. Cambridge: Cambridge University Press. Edge, J. (1989). Mistakes and correction. Harlow: Longman.

Ellis, R. (2005). Instructed language learning and task-based teaching. In E. Hinkel (Ed.), Handbook of research in second language teaching and learning (pp. 713-728). Mahwah, NJ: Erlbaum.

Fakazl1, Ö. (2018). Exploring the Use of Oral Corrective Feedback in Turkish EFL Classrooms: A Case Study at a State University. Kastamonu Ĕ̈itim Dergisi, 26(6), 2177-2187. https://doi.org/10.24106/kefdergi.2971

Harmer, J. (1998). How to teach English. Addison Wesley Longman Limited.

Hendrickson, J.(1978). Error Correction in Foreign Language Teaching. Recent. Theory Research and Practice. The Modern Language Journal, 62(8), 387-398. https://doi.org/ 10.1111/j.1540-4781.1978.tb02409.x

Huang, J., Hao, X. \& Liu, Y. (2013). Error Correction in Oral Classroom. English Language Teaching, 9(12), 98-103. https://doi.org/10.5539/elt.v9n12p98

James, C. (1998). Errors in Language Learning and Use -Exploring Error Analysis. Routledge. Edinburgh: Harlow.

Li, S. F. (2010). The effectiveness of corrective feedback in SLA: A meta-analysis. Language Learning, 60, 309-365. https://doi.org/10.1111/j.1467-9922.2010.00561.x

Lennon, P (1987). Investigating Fluency In ELF: A Quantitative Approach. Language Learning, 40(3), 387-417. https://doi.org/10.1111/j.1467-1770.1990.tb00669.x

Lyster, R., \& Ranta, L. (1997). Corrective Feedback and Learner Uptake: Negotiation of form in communicative Classrooms. Studies in Second Language Acquisition, 19, 37-66. https://doi.org/10.1017/S0272263197001034

Mendelson, D. (1990). How to Correct Errors in the Communicative Language Talking Class. Prospect, 5(1), 67-83.

Morshada, I. (2007). Analysis of Error Correction Done in Different Schools in Dhaka City. BRAC University, Dhaka, Bangladesh.

Nemser, W. (1984). Approximative Systems of Foreign Language Learners. International Review of Applied Linguistic, 9(2), 115-124. https://doi.org/10.1515/iral.1971.9.2.115

Ölmezer-Öztürk, E., \& Öztürk, G. (2016). Types and timing of oral corrective feedback in EFL classrooms: Voices from students. Novitas-ROYAL (Research on Youth and Language), 10(2), 113-133.

Panova, I., \& Lyster, R. (2002). Patterns of corrective feedback and uptake in an adult ESL classroom. TESOL Quarterly, 36(4), 573-595. https://doi.org/10.2307/3588241

Russell, J., \& Spada, N. (2006). The Effectiveness of Corrective Feedback for Second Language Acquisition: A Meta-Analysis of the Research. In J. M. Norris, \& L. Ortega. (Eds.), Synthesizing Research on Language Learning and Teaching (pp. 133-164).

Scrivener, J. (2005). Learning teaching. Oxford: Macmillan.

Sheen, Y. (2007). The Effect of Corrective Feedback on Language Aptitude and Learner Attitudes on the Acquisition of English. Articles. TESOL Quarterly, 41(2), 255-283. 
https://doi.org/10.1002/j.1545-7249.2007.tb00059.x

Swain, M. (1985). Communicative competence: Some rules of comprehensible input and comprehensible output in its development. In S. Gass, \& C. Madden (Eds.), Input in second language acquisition (pp. 235-253). Rowley, MA: Newbury House.

Taipale, P. (2012). Oral Errors, Corrective Feedback and Learner Uptake in an EFL Setting, Master's Thesis, University of Jyväskylä, Fi.

Tomkova, G. (2013). Error Correction in Spoken Practice. MA Thesis. Masaryk University. Truscott, J. (1996). The Case Against Grammar Correction in L2 Writing. Language Learning, 46(2), 327-369. https://doi.org/10.1111/j.1467-1770.1996.tb01238.x

\section{Copyright Disclaimer}

Copyright reserved by the author(s).

This article is an open-access article distributed under the terms and conditions of the Creative Commons Attribution license (http://creativecommons.org/licenses/by/4.0/). 